\title{
Hardened Properties of Self-Compacting Concrete - A Statistical Approach
}

\author{
F.M. Almeida Filho ${ }^{\text {a }}$, B.E. Barragán ${ }^{\text {b, }}$ J.R. Casas ${ }^{b^{*}}$, and A.L.H.C. El Debs ${ }^{\text {a }}$ \\ ${ }^{a}$ Department of Structural Engineering, São Carlos Engineering School, São Paulo University, \\ Av. Trabalhador Sãocarlense, 400, CEP 13566-590, São Carlos, SP - BRAZIL \\ ${ }^{\mathrm{b}}$ Department of Construction Engineering, Universitat Politècnica de Catalunya, \\ C/ Jordi Girona 1-3, 08034 - Barcelona, SPAIN
}

\begin{abstract}
This work presents a statistical study on the variability of the mechanical properties of hardened self-compacting concrete, including the compressive strength, splitting tensile strength and modulus of elasticity. The comparison of the experimental results with those derived from several codes and recommendations allows evaluating if the hardened behavio ur of self-compacting concrete can be appropriately predicted by the existing formulations. The variables analyzed include the maximum size aggregate, paste and gravel content. Results from the analyzed self-compacting concretes presented variability measures in the same range than the expected for conventional vibrated concrete, with all the results within a confidence level of $95 \%$. From several formulations for conventional concrete considered in this study, it was observed that a safe estimation of the modulus of elasticity can be obtained from the value of compressive strength; with lower strength self-compacting concretes presenting higher safety margins. However, most codes overestimate the material tensile strength.
\end{abstract}

Keywords: self-compacting concrete; hardened properties; variability

\footnotetext{
* Corresponding author. Tel.: +34 93401 6513; fax: +34 934054135 .

E-mail address:joan.ramon.casas@upc.edu
} 


\section{INTRODUCTION}

Self-compacting concrete (SCC) can be defined as a concrete that can flow and fill the formwork and embed the reinforcement with no external help, presenting no segregation and consolidating only by its own weight, not needing internal or external compaction [1-3].

Since the first developments in the late 80s, in Japan [3], research and practice are demonstrating the advantages of SCC associated to its high performance in the fresh state. However, and due to its relatively short trajectory, there are less available results regarding the expected hardened properties; either for the mechanical response, durability behavior or intrinsic variability of the material properties. An extensive review to date of the hardened mechanical properties of SCC is presented by Domone [4]. More than 70 studies of hardened mechanical properties of SCC are presented and summarized by Domone, and the conclusion is the significant scatter which is understandable in view of the range of materials, mix designs and test procedures used. Moreover, Domone states that future studies need only be focused on specific or confirmatory data for particular applications [4]. In this sense of particular studies, in [5] is shown how the hardened mechanical properties of SCC vary along the height of slender columns and relates such variations to the mesostructure of the material. In the work by Sonebi and Cevik [6], the feasibility of obtaining properties of the fresh SCC as well as the compressive strength by the use of artificial neural networks (Genetic Programming) is presented. The results of the present study are also obtained in the direction pointed in [4]. In fact, they are focused on a range of compressive strengths 
between 40 and $50 \mathrm{MPa}$, paying more attention to the variability of the mechanical properties, issue where few relevant data is available in the literature and therefore the present research is an step forward in such direction.

SCC has proven advantages enhancing construction productivity, reducing the overall cost of the structure, improving the work environment, achieving sustainable characteristics, increasing the practically allowable reinforcement rate, and increasing the construction rate and overall quality of the cast structures [7-9]. Though not a real disadvantage, a practical drawback could be the necessary quality control of its fresh properties, since this aspect involves the execution of simple but new tests methods to which people at site are still not familiar.

Most guidelines for the use of SCC [10-12] emphasize on ranges and recommendations regarding the fresh properties of the material but much less is discussed regarding its hardened properties. In all cases, the behaviour of SCC in the hardened state is considered at least as good as the conventional counterpart of equivalent strength [4]. However, with important improvements in terms of quality assurance, since SCC is likely to provide a much superior material homogeneity. This aspect can be clearly foreseen when considering real structures, where different levels of compaction are certainly expected from one part of the structure to another; with differences depending on the skill of the workers, characteristics of the application, and location of the concrete in the element.

The objective of this work is to statistically evaluate the variability of the SCC compressive strength $\left(f_{c}\right)$, splitting tensile strength $\left(f_{t}\right)$, and modulus of elasticity $(E)$, 
and compare the experimental test results with those estimated from several codes and recommendations, evaluating if the hardened behaviour of self-compacting concrete can be appropriately predicted by the existing formulations. In this sense, this research presents confirmatory data for SCC with compressive strengths in the range from 40 to $50 \mathrm{MPa}$

Usually SCC contains a higher paste volume, or lower gravel content, and a smaller maximum size aggregate than conventional concrete. Such factors are known to greatly influence the considered material properties, thus, the maximum size aggregate, and gravel and paste contents where chosen as the main variables to be evaluated.

The application of a statistical analysis has been the objective of several researches to evaluate, for instance, the robustness of a certain test or material property; however, care must be taken to not fall into contradictions due to the inappropriate use of the statistical tool or to the small amount of results used in the analysis. The usual drawback of such statistical procedures is that the mean value and standard deviation need a great amount of specimens to avoid a significant error in the estimation of such parameters. In this study, the variability measures have been calculated considering results from 10 to 24 specimens of each SCC mix.

The importance of the present research relies on the lack of published data on the variability of the hardened properties of SCC, which could be affected by its sensibility to minor modifications of the proportions of the component materials, the environment and to the quality control adopted. To obtain reliable experimental data to derive a complete statistical characterization of the most representative mechanical 
parameters of hardened SCC is a must in the way of trying to define, via a calibration procedure, a set of partial safety factors to be used in the application of this specific type of concrete. This will be possible when a sufficient volume of tests would be carried out and their results properly analyzed.

\section{STATISTICAL PARAMETERS ANALYZED}

The statistical parameters analyzed in this work include mean value (M), standard deviation (SD) and the coefficient of variation (COV), for each material property. In the case of $\mathrm{E}$, the bias factor $(\lambda)$, as the ratio between the mean and the nominal value were determined. Between 10 and 24 results of the same concrete (obtained from the same batch) have been considered in the analysis. Also, an evaluation of the theoretical probabilistic distribution function that better fits the experimental data was made for each material property, based on the corresponding frequency analysis (histogram).

The confidence level (CL) is the probability value associated with a confidence interval (CI), which gives an estimated range of values which is likely to include the average value. For this research, a value of $95 \%$ was established for CL (same as applied for ordinary concrete).

Several mathematical models (based in theoretical or empirical results) were used to check the level of accuracy of the formula for conventional concrete available in several codes and recommendations, for the $E$ [13-19] and $f_{t}$ [13-17, 20-22]. All the formulations vary in function of $f_{c}$ and some with the concrete density $[16,18]$. 
The variability obtained from the tests for SCC will be compared with the standard values assumed for ordinary concrete. The variability is measured by parameters like SD and COV. Though SD is more commonly used [23], COV permits a better understanding and easy visualization of the actual variability, since it will not depend on the magnitude of the measured properties. Table 1 shows the relationship between the level of the quality control and the normal variability limits adopted for the compressive strength of ordinary concrete with mean compressive strength higher than $27 \mathrm{MPa}$. As the quality control of the concrete is normally determined only by the compressive strength, there are no reference values similar to those proposed in table 1 for the SD or COV of splitting tensile strength nor for the modulus of elasticity. Therefore, no comparison will be possible in these cases.

\section{MATERIALS}

The cement used for the fabrication of the test specimens was a CEM I 42.5R. The limestone filler had a density of $2630 \mathrm{~kg} / \mathrm{m}^{3}$ and a maximum particle size of 0.125 $\mu \mathrm{m}$. Crushed limestone aggregates included two sands conforming to fractions 0-2 $\mathrm{mm}$ and 0-5 $\mathrm{mm}$ and two gravels of 5-12 $\mathrm{mm}$ and $12-18 \mathrm{~mm}$. The superplasticizer was of the polycarboxylate type, with a density of $1.04 \mathrm{~kg} / \mathrm{m}^{3}$ and a $19 \%$ of solid content.

Three SCC mixes were achieved following the mix design methodology proposed by Gettu et al. [24], where the superplasticizer and filler content is optimized by means of the Marsh cone (EN 445) [25] and mini-slump tests, and the aggregate 
skeleton corresponds to that of best particle packing, determined experimentally without compacting.

Table 2 shows the composition of the SCC mixes and the corresponding selfcompactability measures. As it can be seen, variables include the maximum aggregate size (MAS) and coarse aggregate content. SCC 1 has a MAS of $12 \mathrm{~mm}$ and $19.8 \%$ in volume of gravel, whereas SCC 2 and SCC 3 were optimized with a MAS of $18 \mathrm{~mm}$ and contain a gravel volume of about $29.5 \%$. An increase of the coarse aggregate content reduces the necessary paste volume to achieve self-compactability (cement+filler+water+admixture); hence, a $38.0 \%$ in volume of paste was required in the case of SCC 1, while in the case of SCC 2 and SCC 3 the paste content was of $34.5 \%$ and $35.0 \%$, respectively. Apart from this slight difference in paste content between SCC 2 and SCC 3, which resulted in a much flowable mix in the last case, no other variation was implemented.

As it can be observed from Table 2, the three SCC mixes presented adequate self-compacting characteristics, either in terms of flowability (measured by the slumpflow and V-funnel tests) or passing ability (evaluated by the L-box and J-ring tests). No segregation resistance test was carried out in the fresh state, however, the visual examination of the final spread of the slump-flow showed no signs of segregation (evidenced by a non- uniform coarse aggregate distribution and/or a separation of the components at the perimeter zone). Moreover, cylinders tested under splitting tension were visually examined and a uniform distribution of the coarse aggregate along the height of the specimen was observed, again indicating no segregation. 


\section{EXPERIMENTAL PROGRAM}

The test program included the mixing, casting and testing of $150 \times 300 \mathrm{~mm}$ cylinders of the three SCC mixes for determination of $f_{c}(E N 12390-3)$ [26], $f_{t}$ (EN 12390-6) [27], and E (ASTM C469) [28] up to a 30\% of the concrete compressive strength. As mentioned, three SCCs of the same strength level but varying the MAS and paste content were analyzed (see Table 2). All specimens remained in a humidity chamber $(90 \%<\mathrm{RH}<95 \%)$ until the time of testing, at 28 days. Before testing, the specimens were weighted and the height and diameter measured to calculate the material density in the hardened state.

\section{EXPERIMENTAL RESULTS}

Table 3 presents the results of $f_{c}$, $f_{t}$ and $E$, together with M, SD and COV for all test series. As it can be observed, in general $\mathrm{E}$ is evaluated from at least 20 specimens, while 10-12 specimens where tested to measure $\mathrm{f}_{\mathrm{c}}$ and $\mathrm{f}_{\mathrm{t}}$. Note that results indicated with an asterisk $(*)$ where not considered for the statistical analysis, since those values are out of a $95 \%$ percentile. 


\section{ANALYSIS OF RESULTS AND DISCUSSION}

In general, from Table 3 follows that the variability of $f_{c}$ is lower than that expected for conventional concrete [23] (see Table 1), with E presenting the lowest average $\operatorname{COV}\left(3.6 \%\right.$ ), followed by $\mathrm{f}_{\mathrm{c}}$ and $\mathrm{f}_{\mathrm{t}}$, with COVs of $5.7 \%$ and $14.4 \%$, respectively. Despite that a higher variability may be expected for in situ concrete of a real structure compared to laboratory specimens, this fact can be attributable to two main reasons: on one side the limited number of test results; since it is known that variability increases with the number of tests. And on the other hand, the expected superior homogeneity of SCC, since no compaction takes place. Thus, avoiding the different levels of consolidation that may appear in the samples during casting.

Figs. 1 and 2 show the correlation $\mathrm{E}-\mathrm{f}_{\mathrm{c}}$ and $\mathrm{E}-\mathrm{f}_{\mathrm{t}}$ for the three SCC mixes at 28 days. The linear fits have been separated considering the two main variables that could affect these two properties; the volume of gravel and the maximum aggregate size of the mixes. In this way, a single linear correlation is plotted for SCC 2 and SCC 3 with a MAS of $18 \mathrm{~mm}$ and a gravel volume of approximately $30 \%$, and separated from the linear fit of SCC 1, with a MAS of $12 \mathrm{~mm}$ and a gravel volume of approximately $20 \%$.

As expected, results show an increase of $E$ and $f_{t}$ with $f_{c}$. However more pronounced in the latter case. Though an increase of $\mathrm{E}$ with strength is observed, it is rather gradual; roughly, a $10 \mathrm{MPa}$ increase in $\mathrm{f}_{\mathrm{c}}$ results in a $1 \mathrm{GPa}$ increase of $\mathrm{E}$ for both types of mixes. The $\mathrm{f}_{\mathrm{t}}-\mathrm{E}$ linear correlations appear similar to that of $\mathrm{f}_{\mathrm{c}}-\mathrm{E}$ (Figs. 1 and 2). 
As for conventional concrete, a higher coarse aggregate content or less paste volume (SCC 2 and SCC 3) seems to produce an increase in E for the same compressive strength, as it can be deduced from analysis of the results presented in Table 3 and graphically plotted in Figs. 1 and 2. Fig. 3 shows how E increases with the hardened density of the material, following the expected tendency.

The statistical analysis focused on the M and SD by means of a Normal distribution and a frequency analysis. The Normal distribution is the more commonly used in the case of good quality control of the compressive strength [23]. Figs. 4, 5 and 6 show the frequency histogram and the best-fitted Normal distribution function of $\mathrm{E}, \mathrm{f}_{\mathrm{c}}$ and $\mathrm{f}_{\mathrm{t}}$, respectively. In each case, sub-Fig. (a) refers to the results of SCC1 and subFig. (b) combines SCC2 and SCC3. Additionally, for E, the three mixes are grouped in sub-Fig. (c).

\section{COMPARISON WITH FORMULATIONS}

Table 4 shows the expressions of some Codes and by several authors to predict the values of $E, f_{c}$ and $f_{t}$. In the case of the Norwegian Code, also the material density is required. Such predictions are plotted together with the mean experimental results in Figs. 7 and 8, for $\mathrm{E}$ and $\mathrm{f}_{\mathrm{t}}$, respectively. The experimental values in Fig. 8 were obtained from the average result of compression and tension tests, which gives one value per mix. 
Fig. 7 shows that the relationship $\mathrm{f}_{\mathrm{c}}$ and E obtained experimentally appears slightly above the majority of the code provisions, which is an expected behaviour also in the case of conventional vibrated concrete (Hueste et al. [17]). With particular regard to the Spanish EHE code, that should give the better estimation since the concretes were elaborated with locally available materials in the Catalonian region, all the experimental values appear clearly above predictions for the studied stress range. In general, code estimations approximate better the experimental values at higher compressive strengths, between 45-50 MPa, but clearly underestimate the value of E for SCCs at strengths lower than 40-45 MPa. As mentioned before, the value of Eappeared relatively constant along the analyzed strength interval.

On the other hand, it can be seen from Fig. 8 that the experimental relationship between $\mathrm{f}_{\mathrm{c}}$ and $\mathrm{f}_{\mathrm{t}}$ obtained by splitting tension is beneath the majority of the code provisions, but above the Spanish EHE; with this Code showing a clear underestimation of the concrete tensile strength. From the results of this limited study, the formulation by Hueste et al. [17] seems to give the better estimation at compressive strength levels above $45 \mathrm{MPa}$. For the lower compressive strength, the CEB approximates better the experimental results.

As it can be observed from Fig. 9, the cumulative frequencies obtained from the experimental data are close to a straight line in a Normal probability paper (value of the correlation coefficient equal to 0.98 for $\mathrm{E}$, between 0.94 and 0.96 for $\mathrm{f}_{\mathrm{c}}$ and between 0.96 and 0.98 for $\mathrm{f}_{\mathrm{t}}$ ), therefore, indicating an appropriate fit to the Normal distribution for the three properties analyzed in this study. 


\section{CONCLUSIONS}

This study has presented a statistical analysis on the main resistance properties (the modulus of elasticity, compressive strength and tensile strength ) of three SCC mixes varying the maximum aggregate size, paste and gravel content. Moreover, experimental results have been compared with eight formulations from Codes and authors for the prediction of such material properties.

Results are in accordance with the expected trends for conventional concrete, with $\mathrm{E}$ being sensitive to the paste and gravel content. For a given compressive strength, SCCs elaborated with a larger maximum size aggregate and higher volume of coarse aggregate presented higher values of $\mathrm{E}$. The same behavior was observed when a given tensile strength is considered. At the same time, E noticeably increased with the hardened material density.

When analyzing separately E of SCCs elaborated with a maximum size aggregate of $12 \mathrm{~mm}$ and $18 \mathrm{~mm}$, a somewhat constant value along the analyzed compressive strength interval can be observed. Roughly, a $10 \mathrm{MPa}$ increase in $\mathrm{f}_{\mathrm{c}}$ redounds in a $1 \mathrm{GPa}$ increase of $\mathrm{E}$ for both types of mix.

The relationship between $f_{c}$ and Eobtained experimentally appeared slightly above the majority of the estimations from the considered formulations. In general, formulations approximate better the experimental values at higher compressive 
strengths, between 45-50 MPa, but visibly underestimate E of SCCs at strengths lower than 40-45 MPa.

The experimental relationship between $\mathrm{f}_{\mathrm{c}}$ and $\mathrm{f}_{\mathrm{t}}$ obtained by splitting tension is beneath the majority of the code provisions, however above the Spanish Code. From the results of this limited study, this Code shows a noticeable underestimation of the SCC tensile strength.

The results of the normal distributions at $95 \%$ level of confidence showed that the amount of samples tested were sufficient to show a small variation of the tests, conducting to a reliable conclusion regarding the Gaussian distribution of the mechanical properties tested. Based on the still limited results available, the values $3 \%$, $7 \%$ and $16 \%$ can be used as a rough estimate of the coefficient of variation for $E, f_{c}$ and $\mathrm{f}_{\mathrm{t}}$, respectively.

Considering the special characteristics of the casting process when using SCC, where, for instance, the workmanship influences the final structural homogeneity to a much lesser extent than for normal concrete due to the lack of compaction, the values obtained for cylinder specimens could also be adopted when considering structural elements. However, this issue should be confirmed by further experimental research works. 


\section{ACKNOWLEDGEMENTS}

The first author wishes to thank the support received by Conselho Nacional de Desenvolvimento Científico e Tecnológico $(\mathrm{CNPq})$ for the granted scholarship. Funding from the Spanish Ministry of Science and Technology and the Spanish Ministry of Education and Science, through the grants MAT2003-5530 and PSS 11-2005“HABITAT 2030", respectively, is greatly appreciated. The authors specially thank technicians Camilo Bernad and Miguel Ángel Martin, and Tomàs Garcia, Director of the Structural Technology Laboratory of the Universitat Politècnica de Catalunya.

\section{REFERENCES}

[1] Gomes PCC. Optimization and characterization of high-strength self-compacting concrete. Doctoral Thesis, Universitat Politècnica de Catalunya, Barcelona, 2002.

[2] Okamura H. Self-compacting high-performance concrete. Concrete International, $1997 ; 19(7): 50-54$.

[3] Okamura H, Ozawa K, Ouchi M. Self-compacting concrete. Structural Concrete, 2000; 1(1):3-17.

[4] Domone PL. A review of the hardened mechanical properties of self-compacting concrete. Cement and Concrete Composites, 2007; 29: 1-12 
[5] Torrijos MC, Barragán BE, Zerbino RL. Physical-mechanical properties and mesostructure of plain and fibre reinforced self-compacting concrete. Construction and Building Materials, 2008; 22: 1780-1788.

[6] Sonebi M, Cevik, A. Genetic programming based formulation for fresh and hardened properties of self-compacting concrete containing pulverised fuel ash. Construction and Building Materials, 2009; 23: 2614-2622

[7] Zhu W, Gibbs JC, Bartos PJM. Uniformity of in situ properties of self-compacting concrete in full scale structural elements. Cement \& Concrete Composites, 2001; 23(1):57-64.

[8] Bartos PJM. Measurement of key properties of fresh self-compacting concrete. In: Measurement, testing and standardization: future needs in the field of construction materials, Proceedings, Paris, 5-6 june, 2000.

[9] Almeida Filho FM, El Debs ALHC. Pull-out behavior of deformed bars using high strength self-compacting concrete and high strength ordinary concrete. Ibracon Structural Journal, 2006; 2(1): 44-55.

[10] EFNARC. Specifications and Guidelines for Self-compacting Concrete. 2002, http://www.efnarc.org/pdf/SandGforSCC.PDF 
[11] The European Guidelines for Self-Compacting Concrete: Specification, Production and Use. 2005. http://www.efnarc.org/pdf/SCCGuidelinesMay2005.pdf

[12] Self-Compacting Concrete: a Review. The Concrete Society, UK. Technical Report No. 62. http://www.concrete.org.uk

[13] Spanish Code for Structural Concrete EHE. Real Decreto 2661/1998, Madrid, December 11, 1998. (in Spanish)

[14] Brazilian Association of Technical Standards NBR 6118: Design of Concrete Structures. Rio de Janeiro, 2003. (in Portuguese)

[15] Comité Euro-International du Béton. CEB-FIP Model Code 1990, Thomas Telford, London, 1993.

[16] American Concrete Institute. ACI Committee 318: Building Code Requirements for Structural Concrete. Farmigon Hills, Mich., 1999.

[17] Hueste MBD, Chompreda P, Trejo D, Cline DBH, Keating PB. Mechanical properties of high-strength concrete for prestressed members. ACI Structural Journal, $2004 ; 101(4): 457-465$.

[18] Norwegian Council Standardization. Design of Concrete Structures. Norwegian Code, NS 3473, Oslo, Norway, 1992. 
[19] Gardner NJ, Zhao JW. Mechanical properties of concrete for calculation of long term deformations. In: Proceedings of the Second Canadian on Cement and Concrete, Vancouver-Canada, 1991, p. 150-159.

[20] Olokun FA. Prediction of concrete tensile strength from its compressive strength: evaluation of existing relations for normal weight concrete. ACI Materials Journal, 1991; 88(3):32-39.

[21] Ahmad SH, Shah SP. Structural properties of high strength concrete and its implications for precast prestressed concrete. PCI Journal, 1985; 30(6):92-119.

[22] Burg RG, Ost BW. Engineering properties of commercially avaible high-strength concretes. Research and Development Bulletin - RD104T, Portland Cement Association, Skokie-Illinois, 1992.

[23] Melchers RE. Structural Reliability: analysis and prediction, Ellis Horwood Limited, 1987.

[24] Gettu R, Gomes PCC, Agulló L, Josa A. High-strength self-compacting concrete with fly ash: development and utilization. In: Proceedings Eight CANMET/ACI International Conference on Fly Ash, silica fume, slag, and natural pozzolans in concrete (Las Vegas), ACI SP-221, Farmington Hills, USA: American Concrete Institute, 2004, p. 507-522.

[25] EN 445:1996. Grout for prestressing tendons. Test methods, 1996. 
[26] EN 12390-3:2001 Testing hardened concrete - Part 3: Compressive strength of test specimens, 2001.

[27] EN 12390-6:2000 Testing hardened concrete - Part 6: Tensile splitting strength of test specimens, 2000.

[28] ASTM C469-02e1. Standard Test Method for Static modulus of elasticity and Poisson's Ratio of Concrete in Compression. 


\section{VITAE}

Dr. Fernando Menezes de Almeida Filho is a post-doctoral researcher in the Department of Structural Engineering of the São Carlos Engineering School and has coauthored more than 10 journal articles and conference papers. His research interests include bond behavior, self-compacting concrete, numerical simulations, prestressed concrete structures, and reinforced structures.

Dr. Bryan Erick Barragán is a Research Associate in the Department of Construction Engineering of the Universitat Politècnica de Catalunya and has co-authored more than 60 journal articles and conference papers. His research interests include fibre reinforced concrete, self-compacting concrete, and mix design.

Prof. Joan Ramon Casas is a Professor of Bridge Engineering in the Department of Construction Engineering of the Universitat Politècnica de Catalunya. His research fields include the reliability-based assessment of existing structures, structural health monitoring of existing bridges and repair using FRP. He is authored or co-authored more than 200 journal articles and conference papers.

Prof. Ana Lúcia Homce de Cresce El Debs is an Assistant Professor in the Structural Department of São Carlos Engineering School, at São Paulo University. Her main research interests are self-compacting concrete, fiber-reinforced concrete and structural behavior of composite systems connections. 


\section{LIST OF TABLES}

Table 1. Accepted limits of variability of concrete compressive strength as a function of the quality control

Table 2. Mix proportions and measures of self-compactability

Table 3. Tests results of the SCC mixes ( $f_{c}$ and $f_{t}$ in MPa, $E_{c}$ in GPa)

Table 4. Formulations to predict the $\mathrm{E}$ and $\mathrm{f}_{\mathrm{t}}$ from $\mathrm{f}_{\mathrm{c}}$

\section{LIST OF FIGURES}

Fig. 1. Variability of the correlation between $\mathrm{f}_{\mathrm{c}}$ and $\mathrm{E}$

Fig. 2. Variability of the correlation between $\mathrm{f}_{\mathrm{t}}$ and $\mathrm{E}$

Fig. 3. Modulus of elasticity versus hardened density.

Fig. 4. Normal distribution function for the modulus of elasticity of SCC1(a), SCC2 and SCC3 (b) and the three mixes together (c).

Fig. 5. Normal distribution function for the compressive strength of SCC1(a), SCC2 and SCC3 (b).

Fig. 6. Normal distribution function for the splitting tensile strength of SCC1(a), and SCC2 and SCC3 (b).

Fig. 7. Relationships between the modulus of elasticity and compressive strength for SCC 1, SCC 2 and SCC 3- formulations and experimental values

Fig. 8. Relationship between splitting tensile strength and compressive strength for SCC 1, SCC 2 and SCC 3- formulations and experimental values.

Fig. 9.Normal probability plot for modulus of elasticity (a), compressive strength (b) and splitting tensile strength (c). 
Table 1. Accepted limits of variability of concrete compressive strength as a function of the quality control [23]

\begin{tabular}{lcc}
\hline Quality control & $\begin{array}{l}\text { Accepted limits for the } \\
\text { standard deviation } \\
\left(\mathbf{f}_{\mathbf{c}}>\mathbf{2 7} \mathbf{~ M P a}\right)\end{array}$ & $\begin{array}{l}\text { Accepted limits for the } \\
\text { coefficient of variation }\end{array}$ \\
\hline A (excellent) & 2.7 & $10 \%$ \\
B (average) & 4.0 & $15 \%$ \\
C (poor) & 5.4 & $20 \%$ \\
\hline
\end{tabular}


Table 2. Mix proportions and measures of self-compactability

\begin{tabular}{lccc}
\hline \multicolumn{1}{c}{ Component $\left(\mathbf{k g} / \mathbf{m}^{\mathbf{3}}\right)$} & SCC1 & SCC2 & SCC3 \\
\hline Cement & 363 & 329 & 334 \\
Limestone filler & 109 & 99 & 100 \\
Water & 181 & 165 & 167 \\
Superplasticizer & 6.2 & 5.6 & 5.7 \\
Sand 0-2 mm & 711 & 607 & 603 \\
Sand 0-5 mm & 398 & 340 & 337 \\
Gravel 5-12 mm & 526 & 451 & 447 \\
Gravel 12-18 mm & - & 330 & 329 \\
\hline & & & \\
W/C & 0.45 & 0.45 & 0.45 \\
SP/C (\%) & 1.7 & 1.7 & 1.7 \\
LF/C & 0.3 & 0.3 & 0.3 \\
Paste volume (\%) & 38.0 & 34.5 & 35.0 \\
Sand volume (\%) & 42.2 & 36.0 & 35.0 \\
Gravel volume (\%) & 19.8 & 29.5 & 29.3 \\
\hline & & & \\
Self compactability measures & & & \\
Slump flow, $\mathrm{D}_{\mathrm{f}}(\mathrm{mm})$ & 740 & 570 & 740 \\
Slump flow, $\mathrm{T}_{50}(\mathrm{~s})$ & 1.0 & 1.5 & 1.0 \\
L-box, T60 & $(\mathrm{s})$ & 3.0 & 1.0 \\
L-box, & 1.0 & 0.7 & 1.0 \\
V-funnel, TV (s) & 1.0 & 5.5 & 5.0 \\
J-ring, T50J (s) & 2.5 & 1.0 \\
J-ring, $\mathrm{D}_{\mathrm{fJ}}(\mathrm{mm})$ & 1.0 & 2.0 & 735 \\
\hline
\end{tabular}


Table 3. Tests results of the SCC mixes $\left(f_{c}\right.$ and $f_{t}$ in MPa, E in GPa)

\begin{tabular}{|c|c|c|c|c|c|c|c|c|c|}
\hline \multicolumn{4}{|c|}{ SCC1 } & \multicolumn{3}{|l|}{ SCC2 } & \multicolumn{3}{|l|}{ SCC3 } \\
\hline Cylinder & $\mathbf{E}$ & $\mathbf{f}_{\mathrm{c}}$ & $\mathbf{f}_{t}$ & $\mathbf{E}$ & $\mathbf{f}_{\mathrm{c}}$ & $\mathbf{f}_{\mathbf{t}}$ & $\mathbf{E}$ & $\mathbf{f}_{\mathrm{c}}$ & $\mathbf{f}_{t}$ \\
\hline 1 & 36.15 & 47.70 & & 39.09 & 50.50 & & 37.86 & 44.47 & \\
\hline 2 & 38.25 & 48.59 & & 39.67 & 48.23 & & 37.75 & 43.34 & \\
\hline 3 & 36.38 & 46.56 & & 40.59 & 42.74 & & 37.95 & 38.08 & \\
\hline 4 & 37.04 & 42.38 & & 38.57 & 50.70 & & 38.78 & 43.53 & \\
\hline 5 & 36.08 & 45.54 & & 38.32 & 50.62 & & 38.24 & 42.82 & \\
\hline 6 & 35.60 & 47.39 & & 38.61 & 50.62 & & 36.50 & 43.46 & \\
\hline 7 & 36.97 & 47.19 & & 38.39 & 49.21 & & 38.45 & 45.99 & \\
\hline 8 & 37.39 & 45.75 & & 39.29 & 49.48 & & 38.04 & 39.72 & \\
\hline 9 & 36.46 & 49.10 & & 38.86 & 49.59 & & 38.82 & 41.19 & \\
\hline 10 & 37.22 & 47.98 & & 37.98 & 40.98 & & 38.10 & 43.47 & \\
\hline 11 & 35.68 & 41.90 & & 38.03 & 49.85 & & 36.73 & & 3.75 \\
\hline 12 & 36.88 & & 4.40 & 39.15 & 49.60 & & 38.54 & & 2.74 \\
\hline 13 & 36.56 & & 2.64 & 38.76 & & 3.42 & 37.61 & & 2.44 \\
\hline 14 & 36.96 & & 3.95 & $31.48 *$ & & 3.40 & 39.22 & & 3.05 \\
\hline 15 & 36.17 & & 4.06 & 39.74 & & 3.27 & 36.77 & & 2.47 \\
\hline 16 & 35.21 & & 2.81 & $31.37 *$ & & 4.45 & 35.35 & & 3.10 \\
\hline 17 & 37.31 & & 3.38 & 40.09 & & 4.25 & 39.70 & & 3.59 \\
\hline 18 & 35.56 & & 3.67 & 39.33 & & 3.57 & 39.55 & & 3.94 \\
\hline 19 & 36.40 & & 4.45 & 39.51 & & 4.19 & 38.67 & & 3.12 \\
\hline 20 & 36.16 & & 3.96 & 38.92 & & 3.17 & 37.15 & & 3.36 \\
\hline 21 & 36.53 & & 4.00 & 38.25 & & 3.61 & & & \\
\hline 22 & 35.30 & & 3.65 & 38.98 & & 3.80 & & & \\
\hline 23 & & & & 38.61 & & 4.09 & & & \\
\hline 24 & & & & 38.89 & & 3.51 & & & \\
\hline $\mathbf{M}$ & 36.52 & 46.37 & 3.72 & 38.85 & 48.51 & 3.69 & 37.99 & 42.61 & 3.16 \\
\hline SD & 0.74 & 2.36 & 0.58 & 0.51 & 3.21 & 0.38 & 1.09 & 2.325 & 0.513 \\
\hline $\mathrm{COV}$ & 2.04 & 5.08 & 15.69 & 1.32 & 6.62 & 10.37 & 2.86 & 5.46 & 16.25 \\
\hline
\end{tabular}

* Value not used in the statistical analysis 
Table 4. Formulations to predict the $E$ and $f_{t}$ from $f_{c}$

\begin{tabular}{lll}
\hline & Modulus of elasticity & Tensile strength \\
\hline EHE (1999) [13 & $E_{c}=10000 \cdot \sqrt[3]{f_{c}}$ & $f_{t}=0.21 \cdot \sqrt[3]{f_{c}^{2}}$ \\
NBR 6118 (2003) [14] & $E_{c}=5600 \cdot \sqrt{f_{c}}$ & $f_{t}=0.3 \cdot \sqrt[3]{f_{c}^{2}}$ \\
CEB (1993) [15] & $E_{c}=21.5 \cdot \sqrt[3]{f_{c} / 10}$ & $f_{t}=1.56 \cdot \sqrt[3]{\left(\frac{f_{c}-8}{10}\right)^{2}}$ \\
ACI 318 (1999) [16] & $E_{c}=43 \cdot \rho_{c}^{1.5} \cdot \sqrt{f_{c}} \cdot 10^{-6} *$ & $f_{t}=0.56 \cdot \sqrt{f_{c}}$ \\
Hueste et al. (2004) [17] & $E_{c}=5230 \cdot \sqrt{f_{c}}$ & $f_{t}=0.55 \cdot \sqrt{f_{c}}$ \\
Norwegian Code (1992) [18] & $E_{c}=9.5 \cdot\left(f_{c}\right)^{0.3} \cdot\left(\frac{\rho_{c}}{2400}\right)^{1.5}$ & --- \\
Gardner \& Zao (1991) [19] & $E_{c}=9 \cdot \sqrt[3]{f_{c}}$, for $\mathrm{f}_{\mathrm{c}}>27 \mathrm{MPa}$ & --- \\
Olokun (1991) [20] & --- & $f_{t}=1.39 \cdot f_{c}^{0.69}$ \\
Ahmad \& Shah (1985) [21] & --- & $f_{t}=4.34 \cdot f_{c}^{0.55}$ \\
Burg \& Ost (1992) [22] & --- & $f_{t}=7.3 \cdot \sqrt{f_{c}}$ \\
\hline
\end{tabular}

* where, $\rho_{\mathrm{c}}$ is the concrete density. 


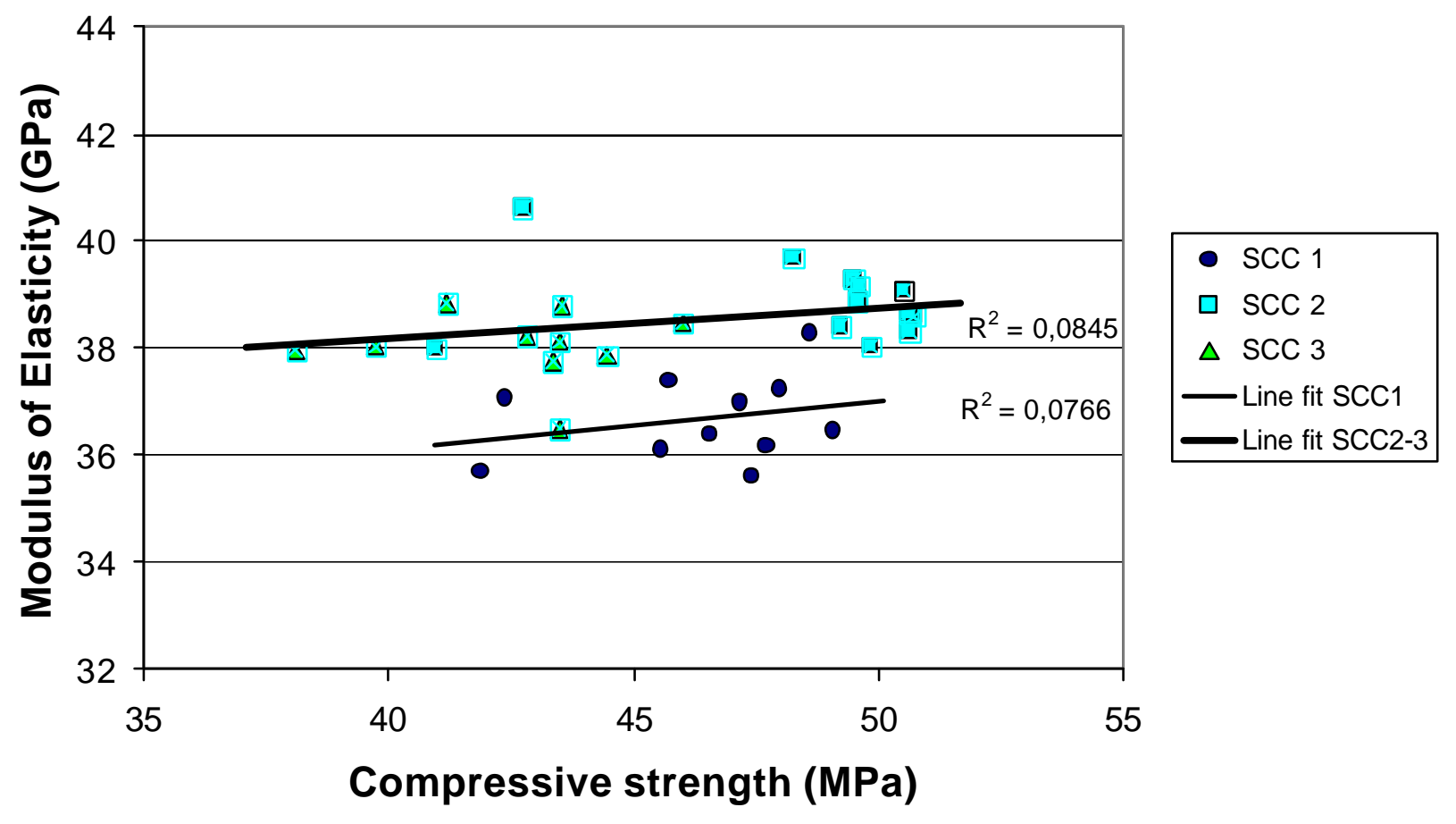

Fig. 1. Variability of the correlation between $f_{c}$ and $E$

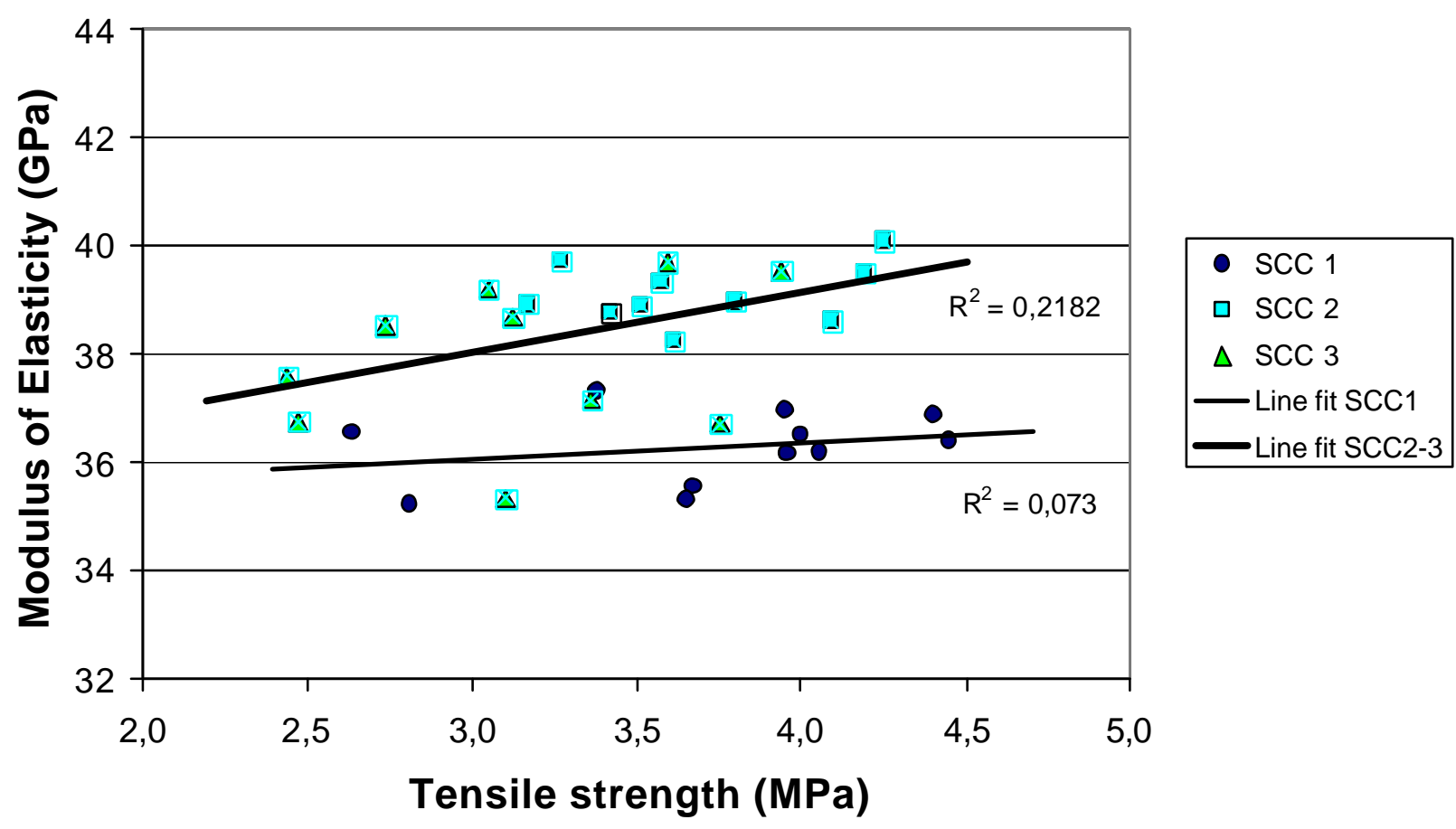

Fig. 2. Variability of the correlation between $\mathrm{f}_{\mathrm{t}}$ and $\mathrm{E}$ 


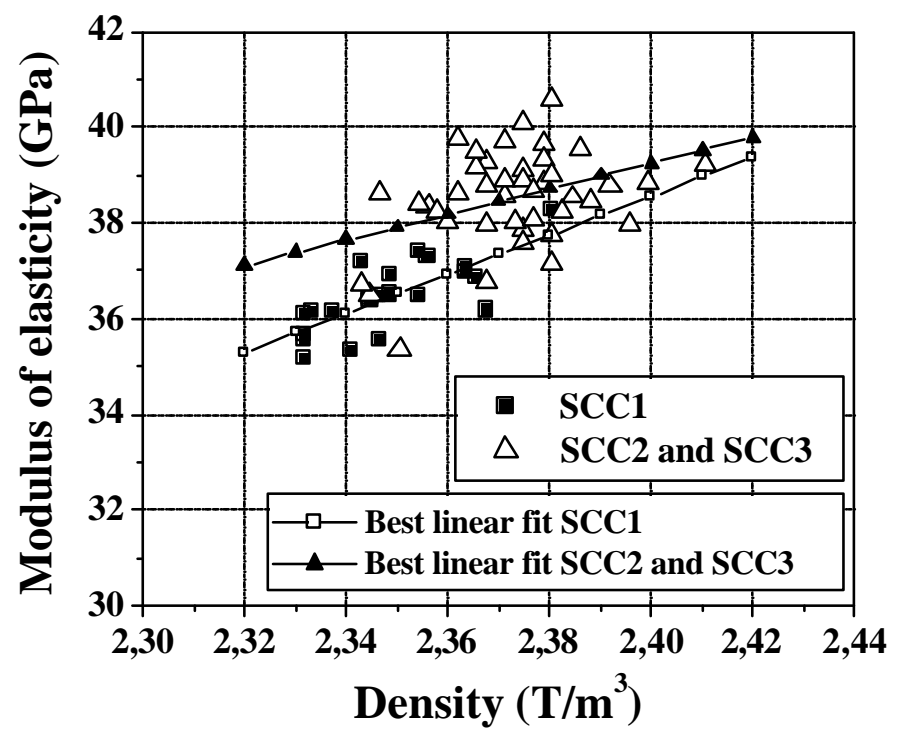

Fig. 3. Modulus of elasticity versus hardened density. 

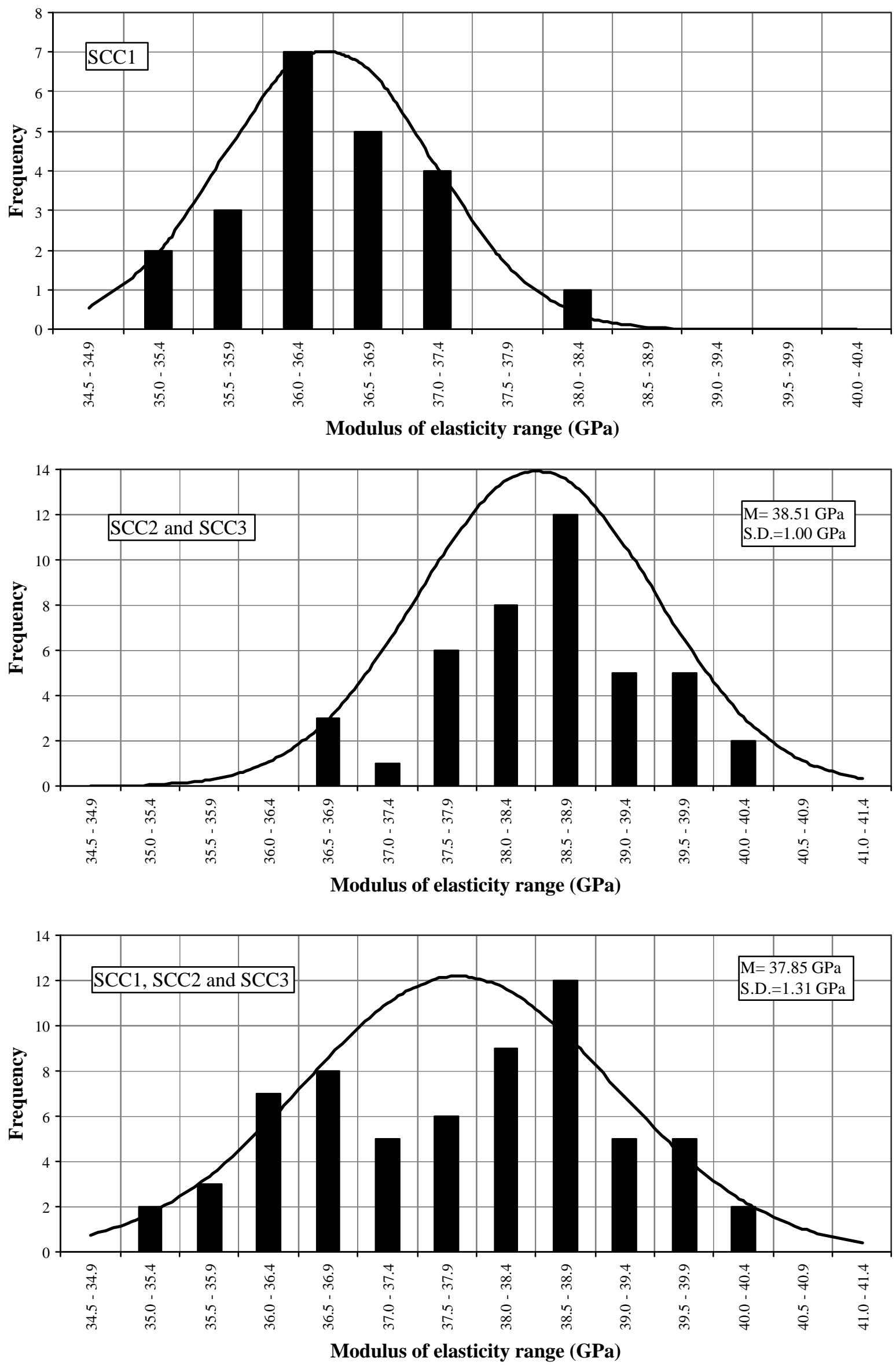

Fig. 4. Normal distribution function for the modulus of elasticity of SCC1(a), SCC2 and SCC3 (b) and the three mixes together (c). 

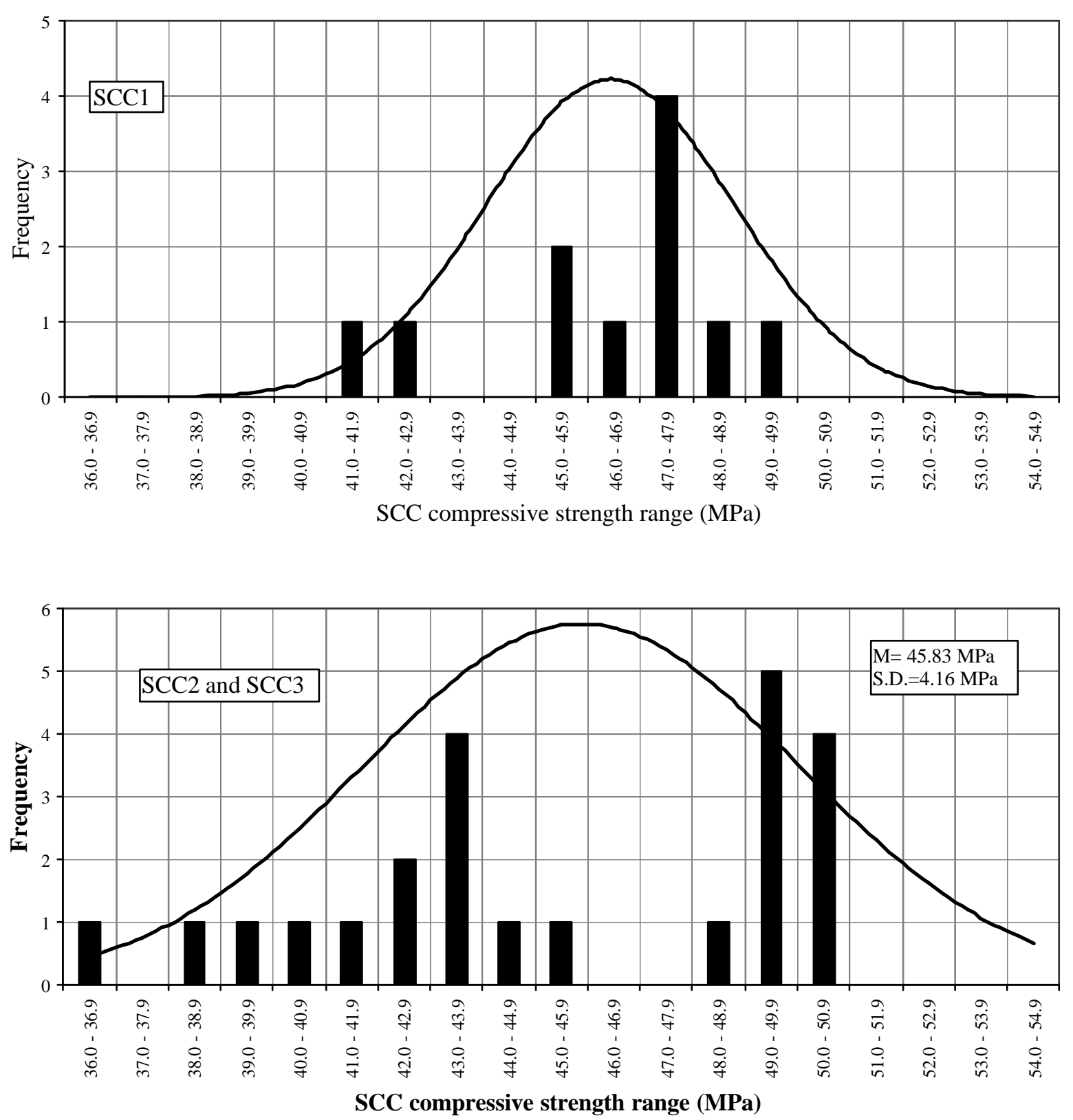

Fig. 5. Normal distribution function for the compressive strength of SCC1(a), SCC2 and SCC3 (b). 


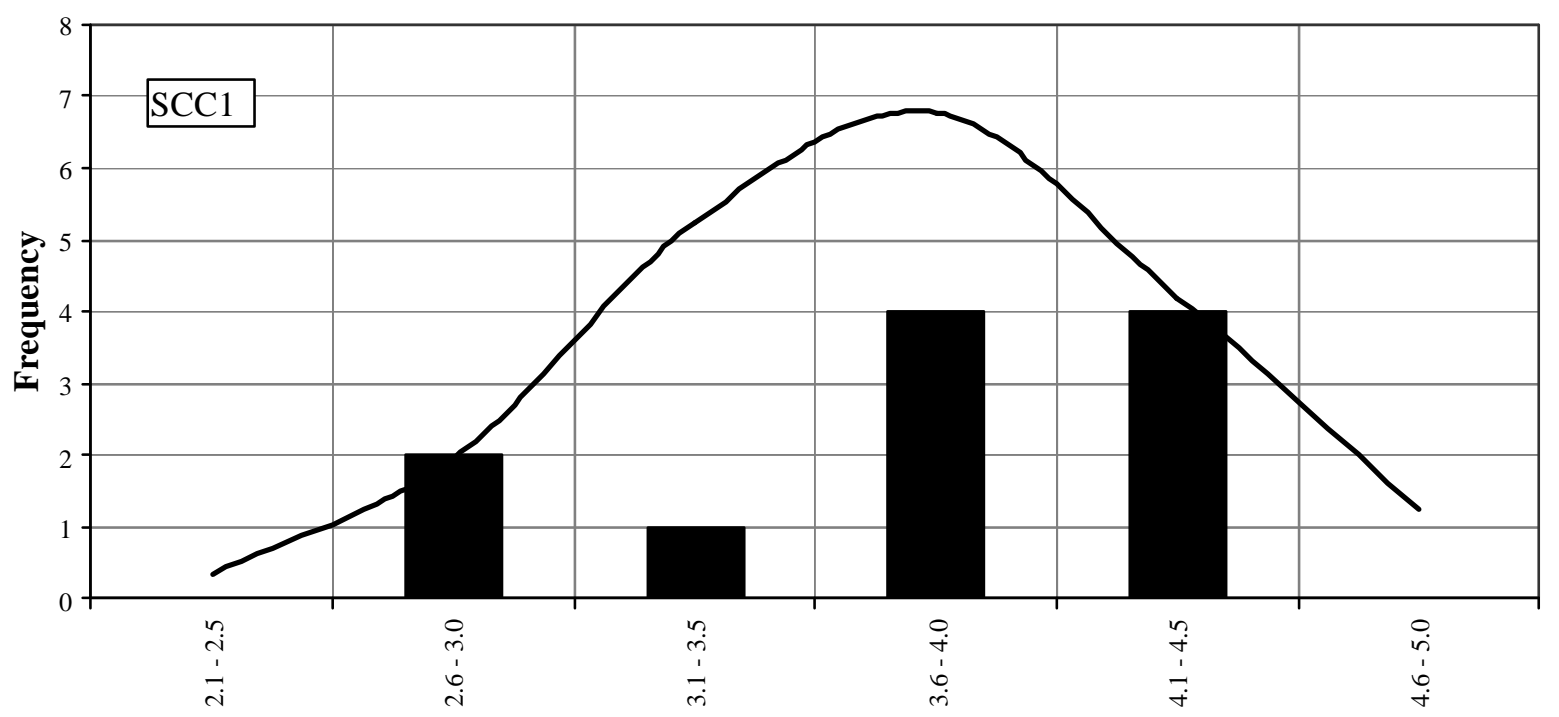

Splitting tensile strength range (MPa)

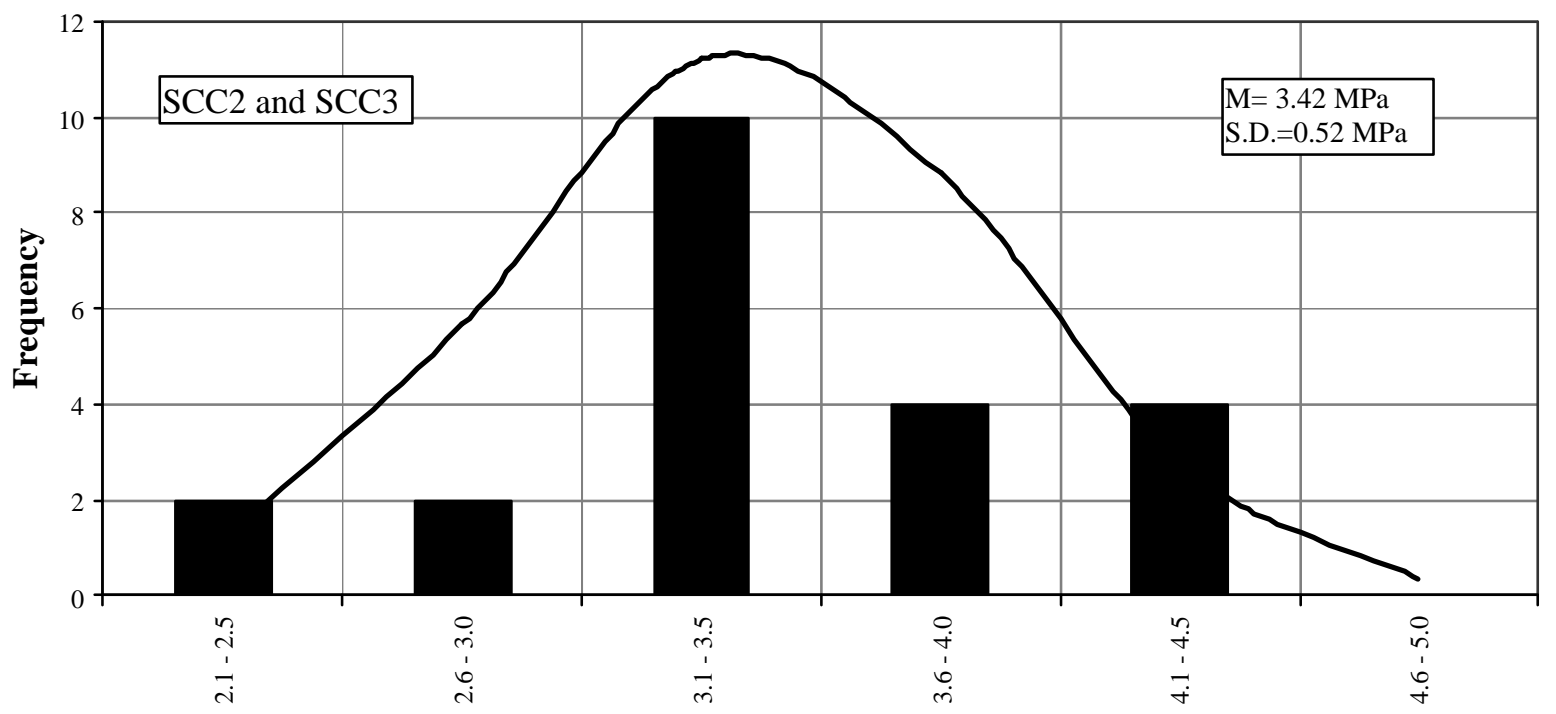

Splitting tensile strength range (MPa)

Fig. 6. Normal distribution function for the splitting tensile strength of $\mathrm{SCC} 1(\mathrm{a})$, and SCC2 and SCC3 (b). 


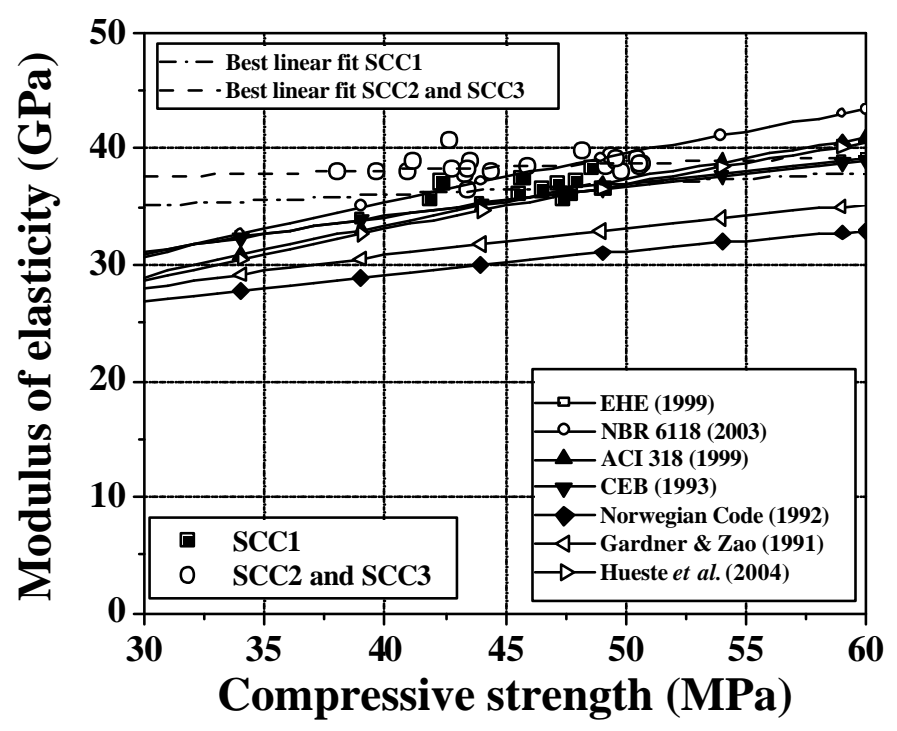

Fig. 7. Relationships between the modulus of elasticity and compressive strength for SCC 1, SCC 2 and SCC 3- formulations and experimental values

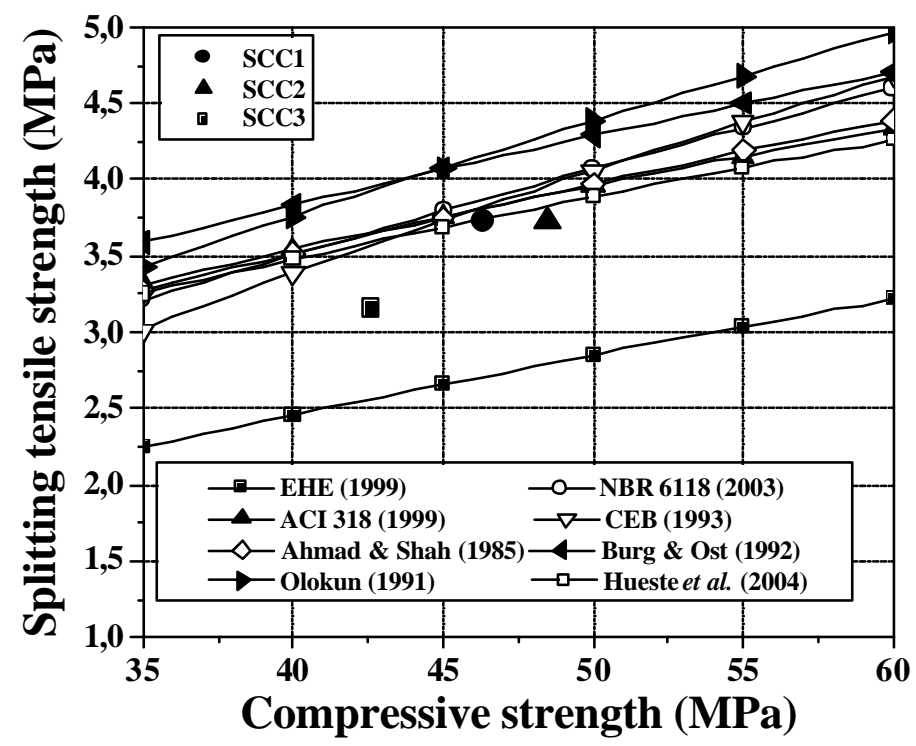

Fig. 8. Relationship between splitting tensile strength and compressive strength for SCC 1, SCC 2 and SCC 3- formulations and experimental values. 
a)

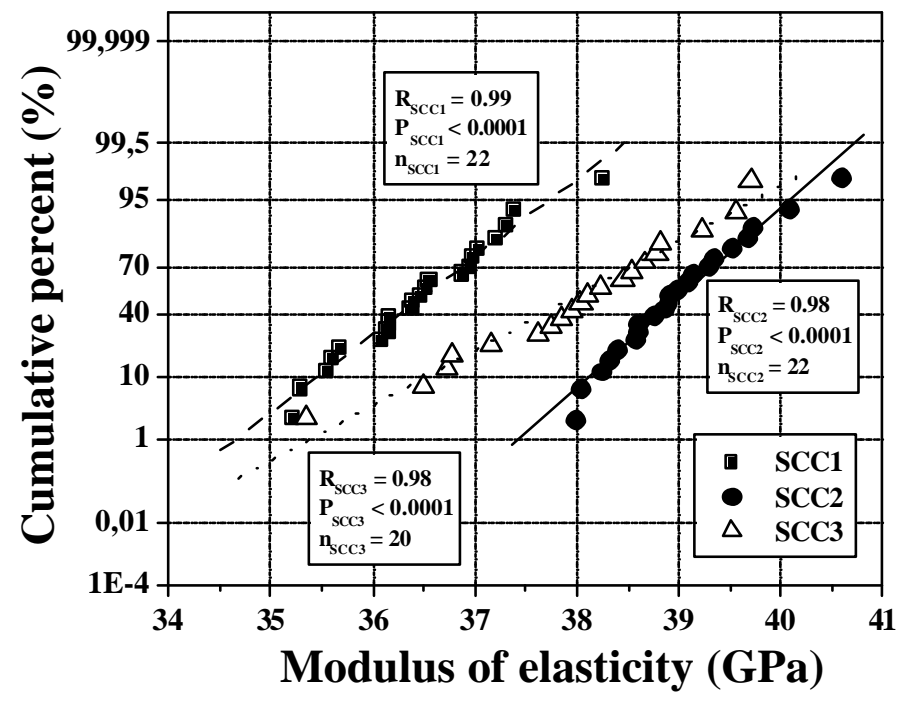

b)

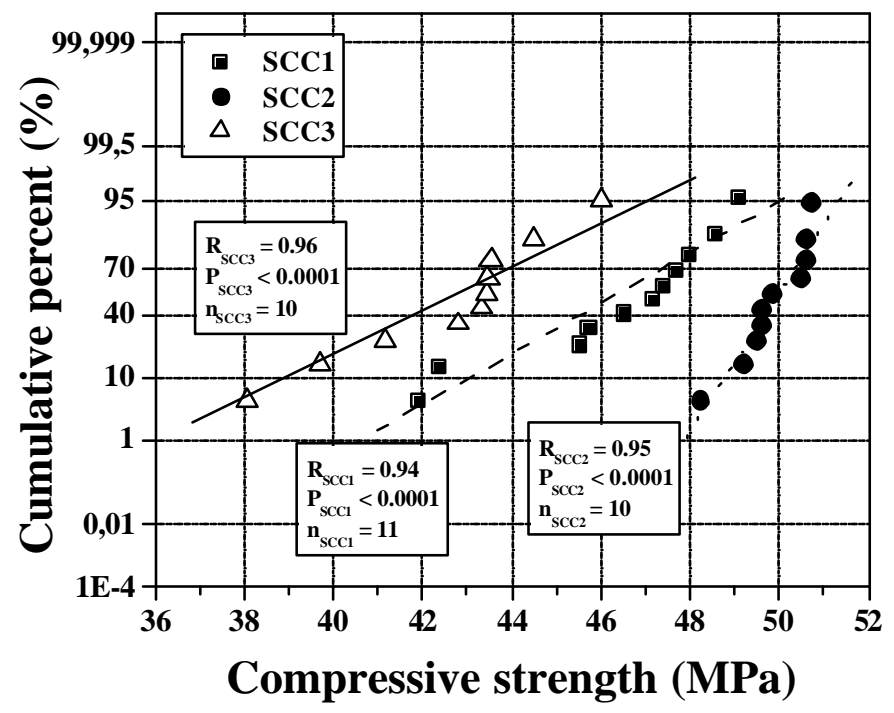

c)

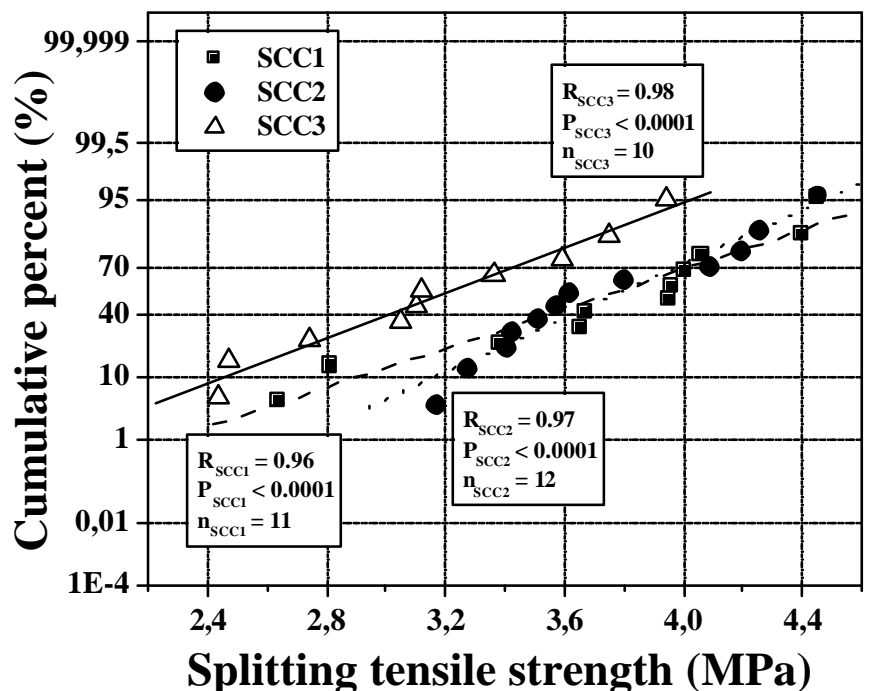

Fig. 9. Normal probability plot for modulus of elasticity (a), compressive strength (b) and splitting tensile strength (c). 